\title{
Diabetic ulcer severity score: clinical validation and outcome
}

\author{
Shiva Kumar T.*, Srinivas Arava, Pavan B. M., Guru Kiran C. S., \\ Chandan G. B., Naveen Kumar M.
}

Department of General Surgery, Sri Siddharatha Medical College, Agalakote, Tumkur, Karnataka, India

Received: 14 June 2016

Accepted: 15 July 2016

*Correspondence:

Dr. Shiva Kumar T.,

E-mail: shiva123kumar.sk2@gmail.com

Copyright: ( ) the author(s), publisher and licensee Medip Academy. This is an open-access article distributed under the terms of the Creative Commons Attribution Non-Commercial License, which permits unrestricted non-commercial use, distribution, and reproduction in any medium, provided the original work is properly cited.

\begin{abstract}
Background: Foot ulcers are a common complication of diabetes and represent a major source of morbidity. Variation in the clinical presentation of this disease has resulted in the paucity of evidence to guide optimal clinical management. A validated scoring system might help the clinicians and researchers in everyday assessment and management of patients or the development and assessment of new therapies. Diabetic ulcer severity score (DUSS) is one of the latest wound based system of classification which needs to be validated. The objective of this study was to clinically validate diabetic ulcer severity score with patient outcome.

Methods: 100 patients were prospectively assessed from October 2012 to March 2014 for four clinical parameters palpable pedal pulses absence (score 1) or presence (score 0), probing to bone yes (score 1) or no (score 0). The site of ulcer- toe (score 0) or foot (score 1) ulcer. Multiple ulcers scored as 1, single ulcers scored as 0. The DUSS was calculated by adding these to a maximum of 4 . Wounds were followed-up until healing or amputation .Kaplan-Meier analysis; Chi- Square tests were used for statistical analysis.

Results: Analyses showed a significantly higher probability of healing for patients with palpable pulses, no probing to bone, toe ulcers, and single ulcer. A decreasing probability of healing for absent pedal pulses, probing to bone, foot ulcers and multiple ulcers with increasing amputation rates.

Conclusions: Lower DUSS score was strongly associated with healing and higher score with amputation.
\end{abstract}

Keywords: DUSS, Diabetic Ulcer, Healing, Amputation

\section{INTRODUCTION}

Foot ulcers are a common complication of diabetes and represent a major source of morbidity. Fifteen percent of diabetics develop foot ulcers during their life time with significant health related decrease in quality of life and consumption of a great deal of healthcare resources. ${ }^{1}$

A number of foot ulcer classification systems for example, the Meggit-Wagner system and the University of Texas systems have been devised in an attempt to categorize ulcers more effectively and thereby allow effective comparison of the outcome of routine management in different centers and treatment strategies. These systems are variously based on the site of ulcer, its depth, and presence/absence of neuropathy, infection and peripheral arterial disease and have been used to compare the outcomes.

DUSS (diabetic ulcer severity score) is one of the latest wound based system of classification which needs to be validated. $^{2}$

\section{METHODS}

\section{Method of collection of data}

Total of 100 diabetic patients with diabetic foot ulcers attending surgical department in Sri Siddharatha Medical College and Hospital were recruited. The baseline 
demographic data which included age, sex, occupation, education status, habits, socioeconomic status and treatment history were taken.

Ulcers were labeled infected if a purulent discharge was present with two other local signs (warmth, erythema, lymphangitis, lymphadenopathy, edema, pain).

Wound depth was evaluated using a sterile blunt probe. The ability to probe to bone with the presence of local or systemic infection and suggestive radiological features provided a clinical diagnosis of osteomyelitis. ${ }^{3}$

Peripheral vascular disease was clinically defined by the absence of both pedal pulses, patients were categorized as having single or multiple ulcerations on the same foot. In patients with multiple ulcers, the wound with the highest grading were selected for analysis. For wounds with identical grading, the larger wound was chosen. Grading of wounds is shown in Table 1.

Table 1: Grades of ulcer.

\begin{tabular}{|ll|}
\hline Ulcer grades & $\begin{array}{l}\text { Wound depth as measured by } \\
\text { sterile blunt probe }\end{array}$ \\
\hline G-1 & Dermis \\
\hline G-2 & Subcutaneous tissue \\
\hline G-3 & Fascia \\
\hline G-4 & Muscle \\
\hline G-5 & Bone \\
\hline
\end{tabular}

Unhealed ulcers were followed up for a minimum period of 6 months. Once a patient's ulcer had healed completely either by primary healing or skin grafting or a lower-limb amputation was performed, the outcome was noted and the patient was deemed to have completed the study.

\section{Diabetic ulcer severity score (DUSS)}

Ulcers were classified by the below mentioned variables. Diabetic ulcer severity score (DUSS) was calculated by adding these separate grading to a theoretical maximum of 4. Parameters and scores are shown in Table 2.

Table 2: Diabetic ulcer severity scoring system.

\begin{tabular}{|lll|}
\hline Parameter & Score $\mathbf{0}$ & Score 1 \\
\hline Palpable pedal pulses & Presence & Absence \\
\hline Probing to bone & No & Yes \\
\hline Ulcer site & Toes & Foot \\
\hline Ulcer number & Single & Multiple \\
\hline
\end{tabular}

Standard treatment care was given to all these patients, which included oral hypoglycemic/insulin, health education, antibiotics if necessary and regular wound care.
Healing was defined as complete epithelialisation. Amputation rate was defined as the percentage of patients undergoing minor or major amputation within the observation period. Toe or forefoot amputations were taken as minor amputation and below or above knee amputation were taken as major amputation.

\section{Follow up}

These patients were followed up in the surgical outpatient clinic once in fortnight for $1^{\text {st }}$ month, then once in a month till the ulcer healed or for a minimum period of up to 6 months. Ulcer healing was assessed.

\section{Inclusion criteria}

Age limit: 20-90 years.

All subjects suffering from diabetes mellitus as per World Health Organization criteria that have foot ulcers.

- Symptoms of diabetes plus random blood sugars $>200 \mathrm{mg} / \mathrm{dl}$.

- (A.) Fasting blood sugars $>126 \mathrm{mg} / \mathrm{dl}$. (B.) Two hour plasma glucose levels $>200 \mathrm{mg} / \mathrm{dl}$.

\section{Exclusion criteria}

- Venous stasis ulcers with diabetes mellitus

- All patients with less than two follow up visits during observation period

- Non diabetic neuropathic ulcers

- Ulcers above the ankle

- All non-diabetics with foot ulcers.

\section{Statistical methods}

Data collected was entered in Microsoft Excel Professional 2010, Microsoft corporation and analyzed using statistical package for social sciences version 20.0, IBM corporation, 2011.

Descriptive statistics such as mean, SD was calculated. Chi-square test was used as test of significance. P-value $<0.001$ is considered as statistically significant.

\section{RESULTS}

In our study out of 100 patients 81 were male and 19 female. Most common age group affected with diabetic foot was 51-60 years followed by 41-50 years with mean age of study group was $57 \pm 12$ years.

Most common DUSS among study population was 1(44 patients) followed by 2 (21 patients). Peripheral pulses were absent in 24 patients while probe to bone test was positive in 43 patients. Gangrene was present in 28 patients. 
Primary healing occurred in 55 patients and total of 45 patients underwent amputation as shown in Table 3. In amputation group 8 were female and 37 were male. 17 patients underwent major amputations among which 13 male and 4 female. 29 patients underwent minor amputation among which 25 were male and 4 female.

Table 3: DUSS versus clinical outcome.

\begin{tabular}{|llll|}
\hline $\begin{array}{l}\text { DUSS } \\
\text { score }\end{array}$ & $\begin{array}{l}\text { Clinical } \\
\text { outcome } \\
\text { Healing }\end{array}$ & $\begin{array}{l}\text { Clinical } \\
\text { outcome } \\
\text { Amputation }\end{array}$ & Total \\
\hline 0 & 14 & 0 & 14 \\
\hline 1 & 37 & 7 & 44 \\
\hline 2 & 4 & 17 & 21 \\
\hline 3 & 0 & 14 & 14 \\
\hline 4 & 0 & 7 & 7 \\
\hline Total & $\mathbf{5 5}$ & $\mathbf{4 5}$ & $\mathbf{1 0 0}$ \\
\hline
\end{tabular}

DUSS score was significantly associated with clinical outcome $(\mathrm{P}<0.001)$ as shown in Table 4 . With every unit increase in DUSS proportion of patient healing decreased significantly.

Table 4: Chi-Square tests for significance of DUSS with clinical outcome.

\begin{tabular}{|llll|}
\hline & Value & df & P value \\
\hline Pearson Chi- Square & 63.133 & 4 & $<0.001$ \\
\hline Likelihood ratio & 78.619 & 4 & $<0.001$ \\
\hline
\end{tabular}

Kaplan Meier analysis showed that patient with DUSS of 0 have $100 \%$ probability of healing. DUSS of 1 had $16 \%$ probability of amputation while that of 2 had $81 \%$ probability of amputation. Patient with DUSS 3 and 4 had $100 \%$ probability of amputation.

\section{DISCUSSION}

Diabetic foot is a serious complication of diabetes and also has significant socioeconomic impact. ${ }^{4}$ Diabetic foot ulcers will complicate the disease in more than $15 \%$ of the people with diabetes during their lifetime. ${ }^{5}$ Prompers $\mathrm{L}$ et al have reported that the lifetime risk of developing a foot ulcer in diabetic patients may be as high as $25 \% .^{6}$ In India, diabetic foot infection is a common cause for hospital admission among diabetic patients. Prevalence of foot infection in diabetic patients in India is $26 \%-34 \%$ and is caused by a number of sociocultural practices. ${ }^{7}$

Most common age group affected with diabetic foot was between 51-60 years, Second group being between 41-50 years. Mean age group was $57 \pm 12$ years. Range of the age was 27-90 years. Similar results in various studies conducted by Viswanathan et al where mean age was 60.6 years, Prompers L et al, a mean age of 64.7 years, Deribe B et al a mean age of 50.7 years, was seen. ${ }^{6-8}$ Paul, et al in a multicenter trial over three continents, found similar finding of mean age of 66.7 years. ${ }^{9}$ Graham lee et al in a Scottish study reported a mean age of 67.4 years. ${ }^{10}$ National hospital discharge survey, looking at 275,000 inpatient records from 500 hospitals since 1996 revealed that elderly diabetics had twice the risk of developing a foot ulcer, three times the risk of developing a foot abscess and four times the risk of developing Osteomyelitis. ${ }^{11}$

In our study we have clinically validated the DUSS score based on the eventual outcome of the wound similar to as shown by the study conducted by Beckert et al. They noted that a lower DUSS score was strongly associated with healing.

In our study according to the Kaplan Meier analysis the probability of healing with score 0 was $100 \%, 84 \%$ probability of healing for score 1 while that of score 2 had $19 \%$ probability of healing. Patient with DUSS 3 and 4 had $0 \%$ probability of healing.

Beckert et al reported primarily healing of $74 \%$ ( $\mathrm{n}=$ $1,000)$, Prompers et al, $77 \%(\mathrm{n}=1,229)$, Oyibo et al, $65 \%$ $(\mathrm{n}=194)$, Jeffcoate et al, 66\% $(\mathrm{n}=449)$, and Gul et al, $72 \%(\mathrm{n}=200){ }^{6,12-14}$

In our study the results showed that presence of gangrene in diabetic foot carries a hazard ratio of 0.351 (95\% CI $0.171-0.718$ ) of amputation or has a $64.9 \%$ hazard of amputation. Prompers L et al observed that peripheral arterial disease and infection has a major impact on healing rates. Armstrong et al. (University of Texas classification system) accordingly, upon analysis of the odds of non-healing per PAD $\times$ infection status, it was only in those patients with both PAD and infection that the odds of non-healing were markedly increased compared with those without PAD or infection. ${ }^{6}$ Jan Apelqvist suggested that there is a need to introduce and recognize decreased perfusion or impaired circulation as indicator for the need of re-vascularisation in the diabetic foot to achieve healing. ${ }^{15}$ Karthikesalingam A et al in his review of various scoring system found that infection and ischemia contribute to impaired healing of ulcer. ${ }^{16}$ Graham lee et al in his study proved that non-infected ulcers were more likely to heal than infected ulcers (81 versus $69 \%$; $\mathrm{P}<0.02)$. The rate of healing for patients with absent pulses was similar to those with neuropathy (89.7 versus $91.7 \%$ ), but in patients who had both clinical criteria, the healing rate was significantly lower $(61.2 \%$; $\mathrm{P}<0.0001) 10$, but however Maria candida Persis using the SAD classification, found that there was no difference in outcome in presence of ischaemia. ${ }^{17}$

In our study, presence of probe to bone carried a hazard ratio of 0.024 (95\% CI $0.005-0.111)$ of amputation or had $97.6 \%$ hazard of amputation (95\% CI 88.9\% $99.5 \%$ ) than absence of probe to bone. Karthikesalingam A et al also in assessment of various scoring system showed that depth of ulcer had an impact on healing ofulcer. ${ }^{16}$ lee $\mathrm{G}$ et al suggested that depth of ulcer as one of the major predictors in healing of ulcer, Maria candida 
Persis proved that there is significant differences in terms of healing were observed for depth of ulcer $(\mathrm{p}<0.002) .^{10,17}$

Diabetes related lower limb major amputation rates reported by Prompers L et al was 5\%. Jeffcoate et al also reported an amputation rate of $5 \%$. In a German cohort, Beckert et al found major amputation rates of $3 \%$, although the data as presented in that report cannot be easily compared because of their unique classification system. Oyibo et al also found similar rates of major amputation of $5 \%$ in their cohort, Jan Apelqvist suggested that an infection in the diabetic foot is a limbthreatening condition and was the immediate cause for amputation in $25-50 \%$ of diabetic patients. ${ }^{6,15}$ Karthikesalingam A, in his systematic review of scoring systems for diabetic foot ulcers he found that surgical removal of bone is required in up to $27 \%$ of these patients with $0.5-5$ per 1000 progressing to major amputation 16 . Graham lee et al in a Scottish study found $12 \%$ of patients required major or minor amputation10 Maria candida Persis in a Brazilian study reported that $12 \%$ of patients underwent amputation. ${ }^{17}$

Margolis et al conducted a cohort study of 24,616 individuals with a diabetic neuropathic foot ulcer treated within a multicenter wound care network. ${ }^{18}$ Total of 1653 $(6.7 \%)$ individuals had an amputation and $46.3 \%$ of these amputations were of a toe or ray (minor amputation). In the more than 10-year follow-up period, the percentage of those who had an amputation varied between $5.6 \%$ and $8.4 \%$. Of those who had an amputation, the percentage that had a minor amputation increased over time from $4.0 \%$ in the earliest years to more than $60 \%$ in the later years of observation.

Overall $45(45.0 \%)$ of 100 people had amputations in our study. Major amputation (below - or above-knee amputation) was done for $11.0 \%$ and minor Amputation (toe or forefoot amputations) was done in $34.0 \%$ of patients which is higher as compared to previous studies. This can be attributed to lower socio- economic status of majority of patients included in our study, which is supported by Kington and Smith theory that economics may play a role in list of complications. ${ }^{19}$ Wachtel MS has also found in his study that comparisons of amputation rates have not been fully performed with specific regard to family poverty and diet, proper footwear, appropriate assessment of foot injuries and timely medical interventional impact the probability of a lower-extremity amputation. ${ }^{19}$

Most commonly ulcers were of DUSS Score of 1 followed by Score 2. Mean score was 1.56 \pm 1.113 . 7 $(9.4 \%)$ out of 44 people with score 1 had amputations, 17 $(25.5 \%)$ out of 21 people with score 2 had amputations, $14(90.6 \%)$ out of 14 people with score 3 had amputations, $7(100.0 \%)$ out of 7 people with score 4 had amputations.
Early Minor amputation can prevent a later major amputation. ${ }^{20}$ Seven $(15.90 \%)$ of 44 patients with score 1 had minor amputation, $14(66.66 \%)$ of 21 patients with score 2 had minor amputation, $10(71.42 \%)$ of 14 patients with score 3 had minor amputations, 3 (42.85\%) of 7 patients with score 4 had minor amputations. Minor amputations were more common in patients with DUSS Score of 2 in our study.

When the DUSS score was compared with the proportion of individuals undergoing amputation it was noted that a total of $3(14.28 \%)$ of 21 people with score 2,4 $(28.57 \%)$ of 14 people with score $3,4(57.14 \%)$ of 7 people with score 4 had major amputations in our study. None of the patients with score 0,1 had major amputation.

In the original study by Beckert et al patients with a score of 0 had no risk of major amputation, while patients with a score of 1 had a $2.4 \%$, patients with a score of 2 had a $7.7 \%$, patients with a score of 3 had an $11.2 \%$, and patients with a score of 4 had a 3.8\%.In comparison in our present study none of the patients with score 0,1 and 2 had major amputation, $16(30.2 \%)$ of 53 people with score 3 had major amputations; $19(55.9 \%)$ out of 34 people with score 4 had major amputations.

\section{CONCLUSION}

DUSS scoring system provides an easy diagnostic tool for predicting probability of healing or amputation by combining four clinically assessable wound based parameters. Study groups can be stratified depending on severity of ulcers and thus can help provide a simple, streamlined approach in clinical setting without need of any advanced investigative tool, but it does not alter the procedure of wound management.

Lower DUSS score was strongly associated with healing and higher score with amputation. Any lasting medical treatment or healing course is doomed without patient involvement. Regular foot examinations are important in detecting co-morbid pre-ulcerative calluses. Surgeon practices, techniques, team work, care strategies still demonstrate the best results.

\section{ACKNOWLEDGEMENTS}

Authors would like to thank heartfully all our patients without whom this study could not be done. Authors also thank Mr. Prakash for his clerical work. I thank the librarian for his co-operation.

Funding: No funding sources Conflict of interest: None declared

Ethical approval: The study was approved by the institutional ethics committee 


\section{REFERENCES}

1. The Expert Committee on the diagnosis and management of diabetes mellitus. Report of the expert committee on the diagnosis and management of diabetes mellitus. Diabetes Care. 1997;20(7);1183-97.

2. Beckert S, Witte M, Wicke C, Königsrainer A, Coerper S. A new wound-based severity score for diabetic foot ulcers. Diabetes Care. 2006;29:988-92.

3. Petrova NL, Foster AV, Edmonds ME. Difference in presentation of Charcot osteoarthropathy in type 1 compared with type 2 diabetes. Diabetes Care. 2004;27:1235-6.

4. Kleopatra A, Doupis J. Management of diabetic foot ulcers. Diabetes Therapy. 2012:(3)1:4.

5. Kalaivani V, Vijay Kumar HM. Short communication diabetic foot in India. Reviewing the Epidemiology and the Amit Jain's. Sch Acad J Biosci. 2013;1(6):305-8.

6. Prompers L, Schaper N, Apelqvist J, Edmonds M, Jude E, Mauricio D, et al. Prediction of outcome in individuals with diabetic foot ulcers: focus on the differences between individuals with and without peripheral arterial disease. The Eurodiale Study. Diabetologia. 2008;51(5):747-55.

7. Viswanathan V, Madhavan S, Rajasekar S, Chamukuttan S, Ambady R. Urban-rural differences in the prevalence of foot complications in SouthIndian diabetic patients. Diabetes care. 2006;29(3):701-3.

8. Deribe BK, Michael W, Nemera G. Prevalence and factors influencing diabetic foot ulcer among diabetic patients attending Arbaminch hospital, South Ethiopia. J Diabetes Metab. 2014;5(1):2-7.

9. Ince P, Abbas ZG, Lutale JK, Basit A, Ali SM, Chohan F, et al. Use of SINBAD classification System and score in comparing outcome of foot ulcer management on three continents. Diabetes Care. 2008;31;964-7.

10. Leese G, Schofield C, McMurray B, Libby G, Golden J, MacAlpine R, et al. Scottish foot ulcer risk score predicts foot ulcer healing in a regional specialist foot clinic. Diabetes care. 2007;30(8):2064-9.

11. Reed JF. An audit of lower extremity complication in patients with diabetes mellitus. International Journal Lower Extremity Wounds. 2004;3:161-4.

12. Oyibo SO, Jude EB, Tarawneh I, Nguyen HC, Armstrong DG, Harkless LB, et al. The effects of ulcer size and site, patient's age, sex and type and duration of diabetes on the outcome of diabetic foot ulcers. Diabet Med. 2001;18:133-8.

13. Jeffcoate WJ, Chipchase SY, Ince P, Game FL. Assessing the outcome of the management of diabetic foot ulcers using ulcer-related and personrelated measures. Diabetes Care. 2006;29:1784-7.

14. Gul A, Basit A, Ali SM, Ahmadani MY. Role of wound classification in predicting the outcome of diabetic foot ulcer. J Pak Med Assoc. 2006;56:444-7.

15. Apelqvist, Jan. Diagnostics and treatment of the diabetic foot. Endocrine. 2012;41(3):384-97.

16. Karthikesalingam A, Holt PJ, Moxey P, Jones KG, Thompson MM, Hinchliffe RJ. A systematic review of scoring systems for diabetic foot ulcers. Diabetic Medicine. 2010;57(5):544-9.

17. Parisi MC, Zantut-Wittmann DE, Pavin EJ, Machado $\mathrm{H}$, Nery M, Jeffcoate WJ. Comparison of three systems of classification in predicting the outcome of diabetic foot ulcers in a Brazilian population. European Journal of Endocrinology. 2008;159(4):417-22.

18. Margolis DJ, Allen-Taylor L, Hoffstad O. Diabetic neuropathic foot ulcers and amputation. Wound Repair Regen. 2005;13:230-6.

19. Wachtel MS. Family poverty accounts for differences in lower-extremity amputation rates of minorities 50 years old or more with diabetes. J Natl Med Assoc. 2005;97(3):334-8.

20. Buckley CM, Ali F, Roberts G, Kearney PM, Perry IJ, Bradley CP. Timing of access to secondary healthcare services for diabetes management and lower extremity amputation in people with diabetes: a protocol of a case-control study. BMJ open. 2013;3(10):e003871.

Cite this article as: Kumar ST, Arava S, Pavan BM, Guru Kiran CS, Chandan GB, Kumar NM. Diabetic ulcer severity score: clinical validation and outcome. Int Surg J 2016;3:1606-10. 